\title{
Study the Behavior of Autistic Patients and Analysis of Amygdala Region of Brain to Explore Autism
}

\author{
Nur-Un-Nahar Nury, ${ }^{1, *}$, Suraiya Yasmin ${ }^{2}$ \\ ${ }^{1}$ Department of CSE, Jahangirnagar University, Bangladesh \\ ${ }^{2}$ Department of CSIT, Bangabandu Sheikh Mujibur Rahman Agricultural University, Bangladesh
}

Copyright (C) 2015 by authors, all rights reserved. Authors agree that this article remains permanently open access under the terms of the Creative Commons Attribution License 4.0 International License

\begin{abstract}
Autism is a great concern to the present world. It is a developmental disorder of human brain that occurs in the first 3 years of life. Autism is an assortment of behavioral problems such as restricted happiness, sensory sensitivities and repetitive behaviors. The Amygdala Region (AMG) along with other cortical regions of human brain plays a vital role in socio-emotional behavior in controls and hypoactive in patients with autism. Functional magnetic resonance imaging (fMRI) shows the young children with autism have a larger amygdala than typically developing children. In pursuing the work, fMRI images of AMG for control and autistic patients are considered as input images for behavior analysis. Four categories of fixation such as, Neutral-fixation, Happy-fixation, Sad-fixation, and Fearful-fixation are considered. Initially, the fMRI images are processed for segmentation using Level Set Method, the produced images of which are further processed for thresholding and morphological operation. The proposed approach has been implemented in MATLAB 9.00. Finally, it has been observed that AMG region of brain is to be hyper functional in autistic patients rather than hypo functional in controlled patients.
\end{abstract}

Keywords Autism, fMRI(Functional Magnetic Resonance Imaging), AMG(amygdala), Anxiety

\section{Introduction}

Autism is a potential threat to the present world. A great number of individuals have been suffering from autism worldwide. Autism is part of a spectrum disorder which is characterized by a triad of symptoms, including deficits in all aspects of social reciprocity; sensible communication deficits and language delays; and an assortment of behavioral problems, such as restricted interests, repetitive behaviors and so on [1]. Specific causes of autism have not yet been known and there's no medication of it. There is no obvious core mechanism that could explain the assortment of symptoms found in autism; the triad of deficits suggests that a dissimilar set of neural systems are affected. Its early inception and familial pattern strongly suggest a biological basis, and, in fact, there are now substantial data implicating brain based as well as genetic mechanisms [2]. However, the pattern of brain irregularity is discrete, because autism spares many perceptual and cognitive systems. The neurobiological explanation of autism focuses on deficit of complex information processing as a necessary constituent. A key feature of normal social functioning in humans is the processing of faces, which allows people to identify individuals and enables them with the capability to understand the mental state of others [3]. It is well recognized from functional magnetic resonance imaging (fMRI) studies. The amygdala is one of several brain regions supposed to be pathological in autism. The young children with autism have a larger amygdala than typically developing children.[4] Past qualitative observations of the autistic brain suggest that the increased cell density in some nuclei of the postmortem autistic amygdala. The quantitative stereological study of the autistic brain counted and measured neurons in several amygdala subdivisions of 9 autism male brains and 10 age-matched male control brains [5].The amygdalaoid complex was outlined on coronal sections then partitioned into five reliably defined subdivisions: (1) lateral nucleus, (2) basal nucleus, (3) accessory basal nucleus, (4) central nucleus, and (5) remaining nuclei [6-8]. There is no difference in overall volume of the amygdala or in individual subdivisions. There are also no changes in cell size. However, there are significantly fewer neurons in the autistic amygdala overall and in its lateral nucleus. In combination with the findings from previous magnetic resonance imaging studies, the autistic amygdala appears to undergo an irregular pattern of postnatal development that includes early enlargement and ultimately a reduced number of neurons. It will be important to find out in future studies whether neuron loss in the amygdala is a steady characteristic of autism and whether cell loss occurs in other brain regions as well [9].

Amygdala is a fundamental constituent of the social 
system and involved in detecting and reacting to environmental threats and if the amygdala is impaired in autism, it may be more responsible for alterations in fear and anxiety rather than social behavior. Individuals with larger amygdala had larger and more complex social networks [10]. Four categories of fixation that is, Neutral-fixation, Happy-fixation, Sad-fixation, Fearful-fixation are considered for examine the functional activity of AMG from fMRI images. The proposed approach has been implemented in MATLAB 9.00 The fMRI images are taken as the input images and after that Level Set Method has been applied for segmentation. The resulted images obtained after segmentation is taken as input for thresholding and morphological operation. The work has been done for autism behavior analysis compared to the controls based on the activation of AMG. It has been observed that AMG to be hyper functional in autism rather than hypo functional as controlled patients.

To understand autism and their remedies a number of research papers $[11,12,13,14,15,16$, and 17] have been published. Many researcher studies autism [18, 19, 20] considering amygdala region of brain as a major culprit.

\section{Amygdala Region}

The amygdala is an almond-shaped brain region located in the anterior portion of the temporal lobe. It is occupying a volume of approximately $2.25 \mathrm{~cm}^{3}$ on each side [21], it makes up just about $0.3 \%$ of the volume of the human brain. Generally, the amygdala is composed of several distinct groups of cells, usually termed the lateral, basal and accessory basal nuclei, which are jointly termed the basolateral amygdala [22].

\section{Materials and Methods}

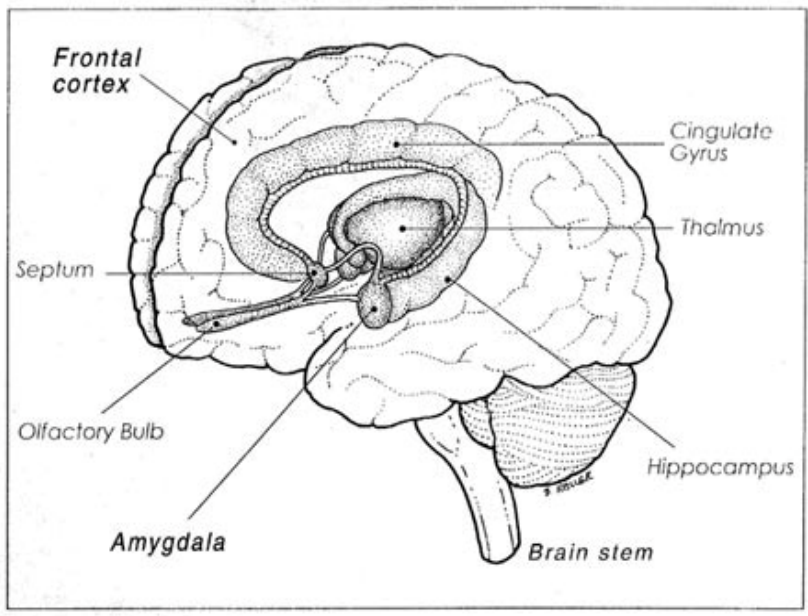

Figure 1. Amygdala on Human Brain

The aim of research is the new medical image segmentation technique Based on Level Set Method.

Level set methods are a conceptual framework for using level sets as a tool by which the numerical analysis is done on surfaces and shapes. The advantage of the level set model is that one can perform numerical computations relating curves and surfaces on a fixed Cartesian grid without having to parameterize these objects (this is called the Eulerian approach). Also, the level set method makes it very easy to follow shapes that change topology, for example when a shape splits in two, develops holes, or the reverse of these operations [23].

The level set method is a simple and versatile method for computing and analyzing the motion of an interface $\Gamma$ in two or three dimensions. $\Gamma$ bounds a (possibly multiply connected) region $\Omega$. The goal is to compute and analyze the subsequent motion of $\Gamma$ under a velocity field v. This velocity can depend on position, time, the geometry of the interface and the external physics [24].The main steps employed for new medical image segmentation technique Based on Level Set Method shown in Fig2. An initial threshold (T) is chosen. The image is segmented into object and background pixels as

$$
\begin{aligned}
& \text { i } 1 \ldots \text {.. if ...f } f(x, y)>1 \\
& g(x, y)=\mathbf{i} \\
& \hat{\mathbf{\imath}}^{0 \ldots . . . i f} \ldots f(x, y)<1
\end{aligned}
$$

Provides a binary image as follows:
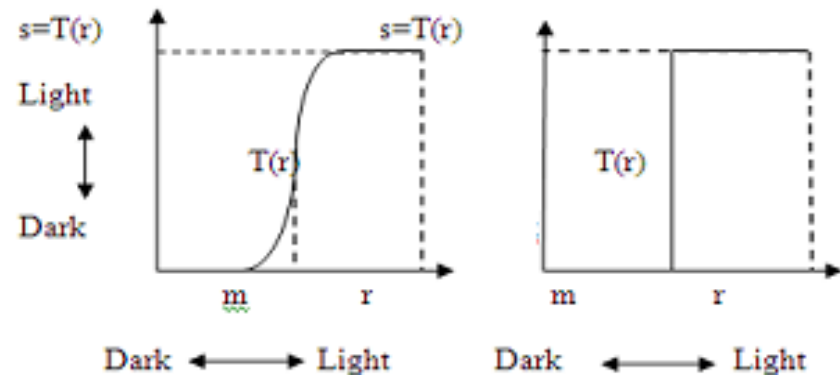

Figure 2. Level set Segmentation

\section{Morphological Operation (Erosion)}

The erosion operator takes two pieces of data as inputs in which the first is the image to be eroded and the second is a set of coordinate points known as a structuring element (also known as a kernel) [25].The erosion of the binary image A by the structuring element $B$ is defined by

$$
A \mathbf{q} B=\{z \boldsymbol{\mathbf { T }} E \mid B » \boldsymbol{\mathbf { I }} A\}
$$
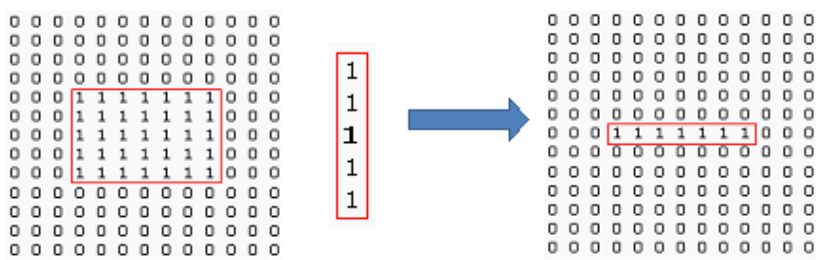

Figure 3. Morphological processing 


\section{Results and Discussion}

The proposed approach has been implemented in MATLAB 9. The images shown in figure 4 are taken as the input images for both control and autistic. The Level Set method is applied for image segmentation. The segmented images are taken as input for morphological operation. Then output images are produced which are shown in the following figures.

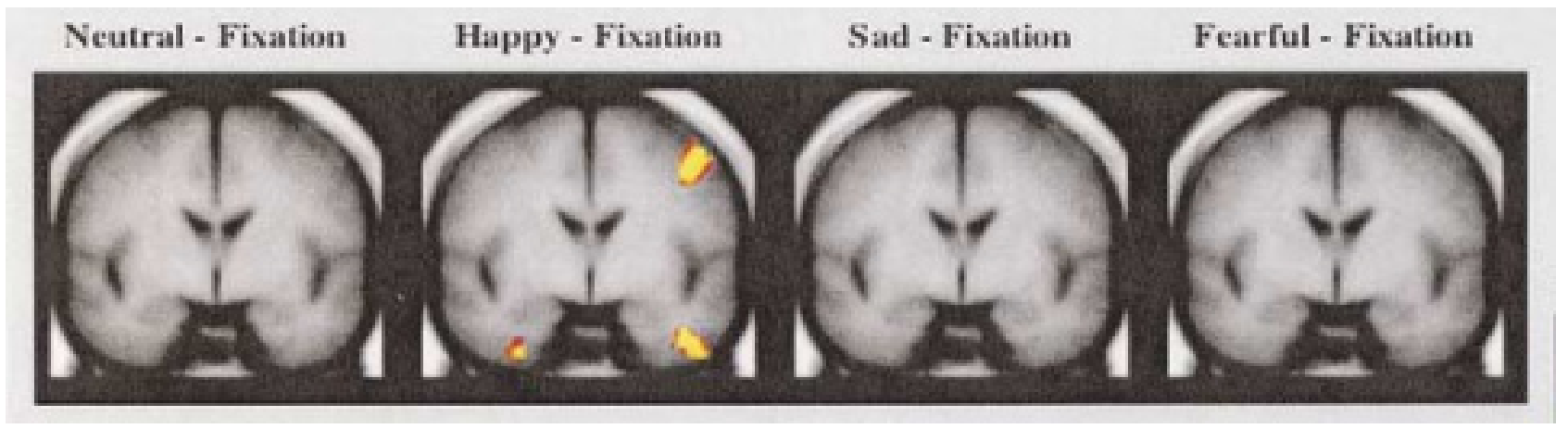

(a) Control group

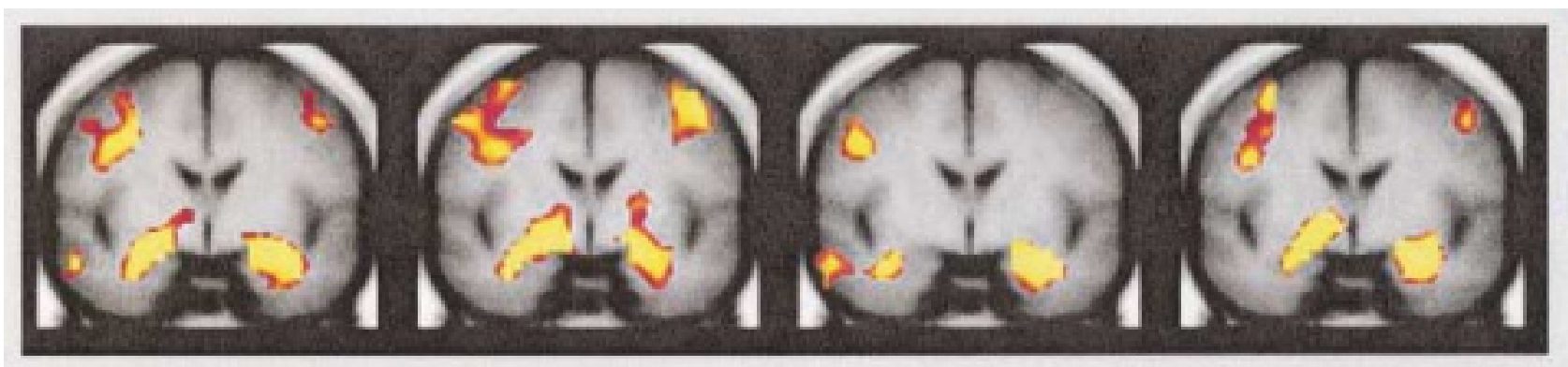

(b) Autistic group

Figure 4. Input images for both control and autistic.

\section{Neutral-fixation}

Figure $5 \mathrm{a}$ and $6 \mathrm{a}$ shows the fMRI input images of both control and autistic brain for neutral fixation. The thresholding, segmentation and morphological operation are applied on those images which are shown in $5 \mathrm{~b}$ and $5 \mathrm{c}$ for control $\&$ in $6 \mathrm{c}$ and $6 \mathrm{~d}$ for autistic people. After segmentation the output images are produced this is shown in figure $5 \mathrm{~d}$ and $6 \mathrm{~d}$ for both control and autistic. The active brain region is marked by red lines. Comparing figure $5 \mathrm{~d}$ and $6 \mathrm{~d}$, it is clearly visualized that there is less amygdala activation in control than the autistic that means it is hyper functional in autism rather than hypo functional in control as established by David.

The same work has been done for happy, sad, fearful fixation. For all fixations, comparing the output images for both control and autistic, , it is clearly visualized that there is less amygdala activation in control than the autistic that means it is hyper functional in autism rather than hypo functional in control as established by David.

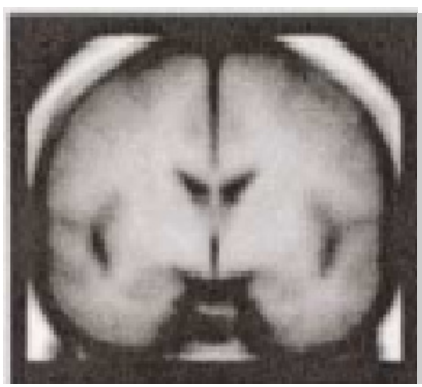

a. Input image

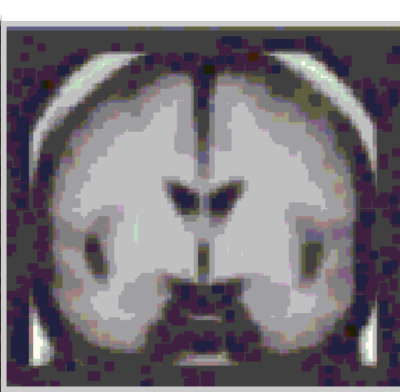

b. Thresholding

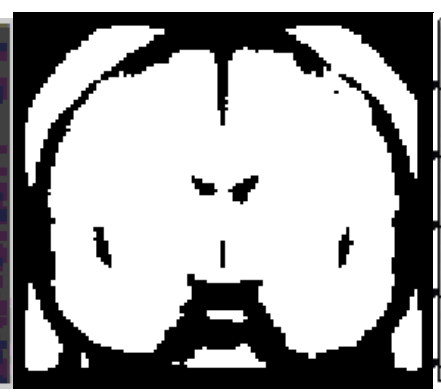

c. Segmentation \&Morphological operation

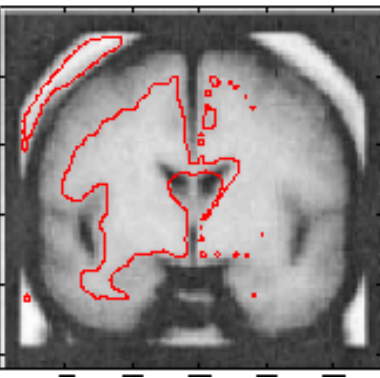

d. Output image

Figure 5. Input image and processed output images for control people. 


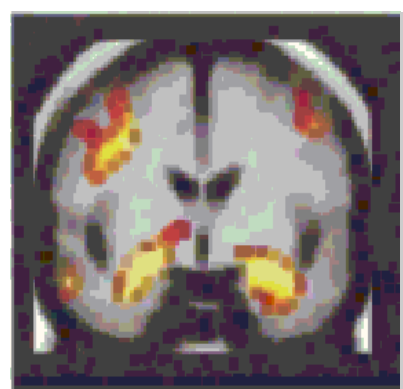

a. Input image

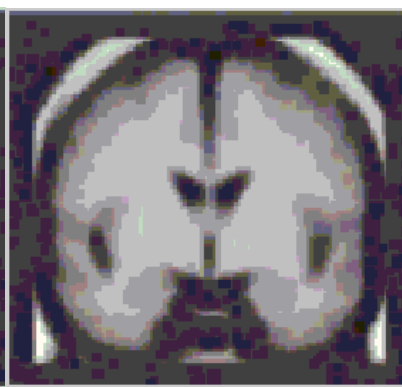

b. Thresholding

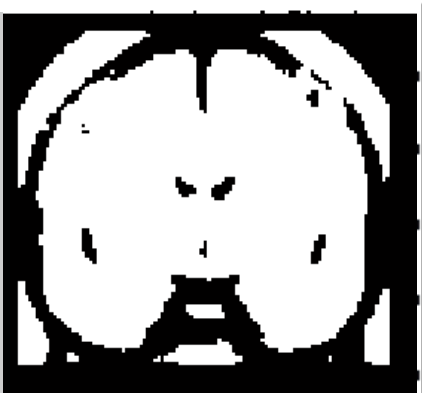

c. Segmentation \&Morphological operation

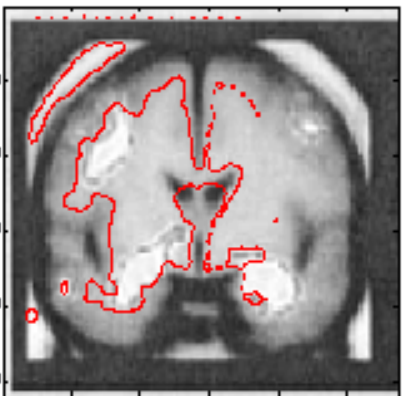

d. Output image

Figure 6. Input image and processed output images for Autistic people.

\section{Happy-fixation}

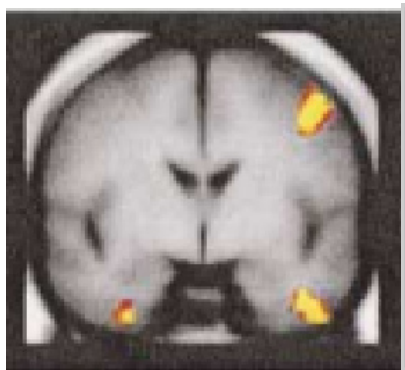

Input image

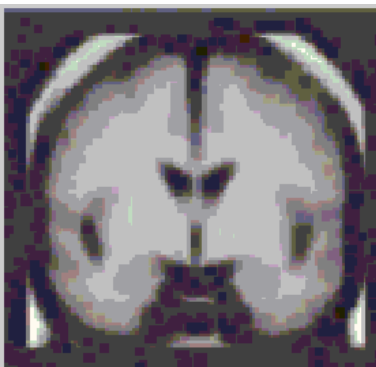

Thresholding

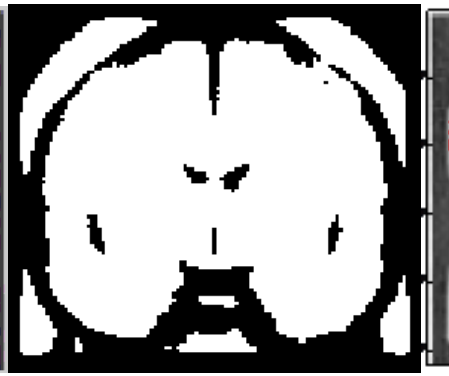

Segmentation \&Morphological operation

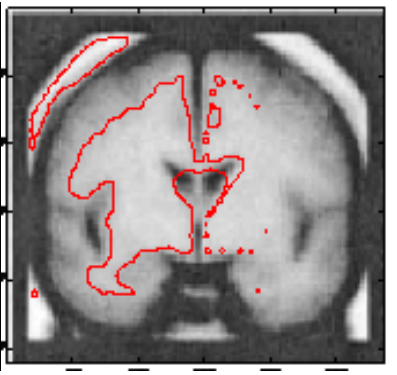

Output image

Figure 7. Input image and processed output images for control people.

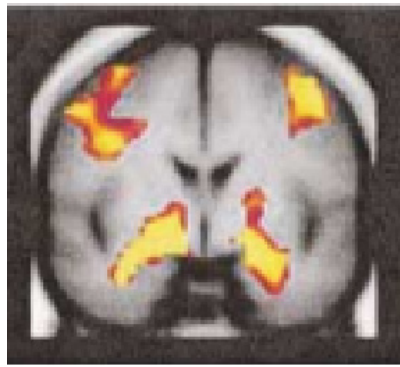

Input image

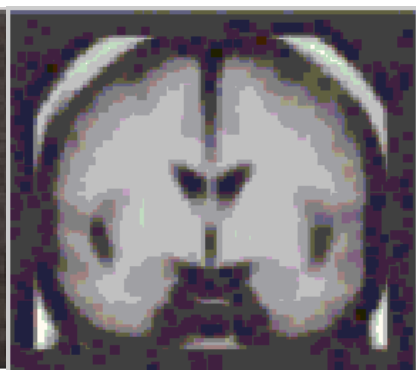

Thresholding

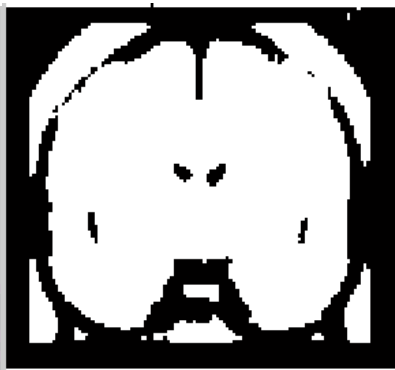

Segmentation \&Morphological operation

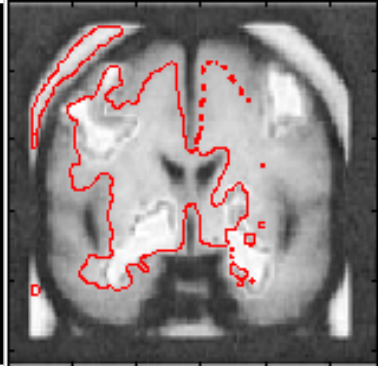

Output image

Figure 8. Input image and processed output images for Autistic people.

\section{Sad-fixation}

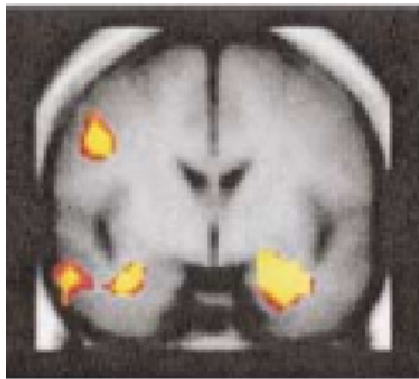

Input image

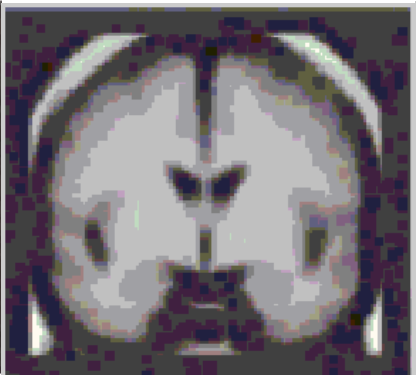

Thresholding

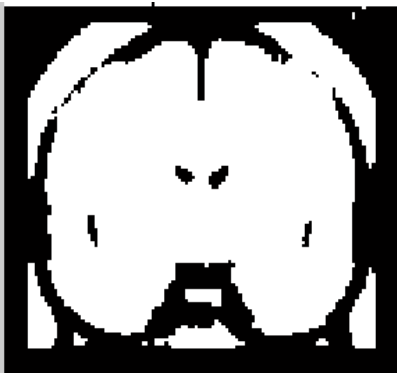

Segmentation \&Morphological operation

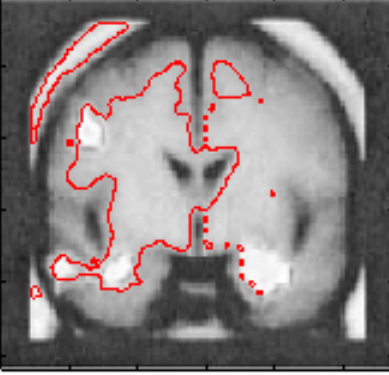

Output image

Figure 9. Input image and processed output images for Autistic people. 


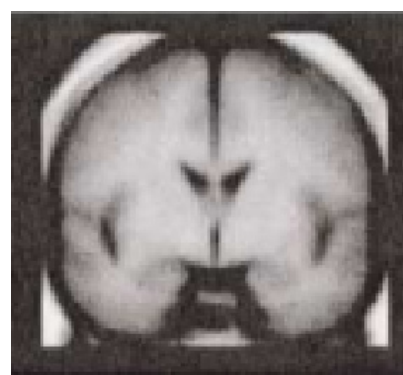

Input image

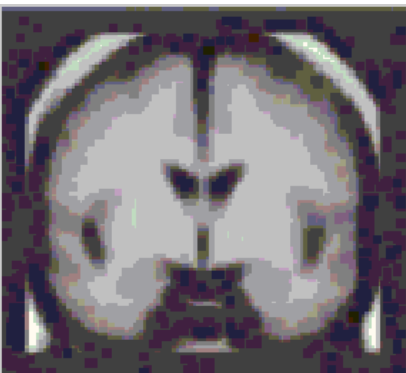

Thresholding

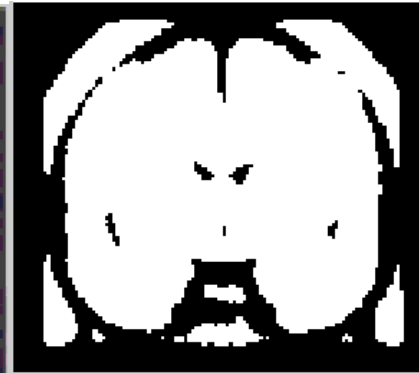

Segmentation \&Morphological operation

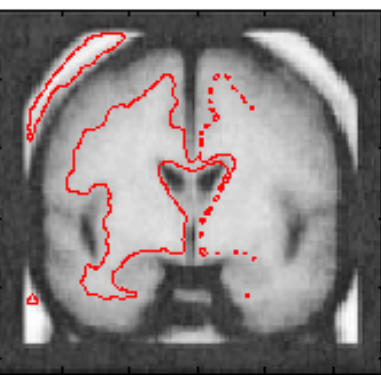

Output image

Figure 10. Input image and processed output images for control people.

\section{Fearful-fixation}

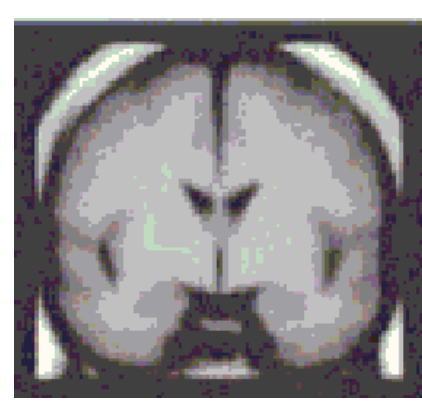

Input image

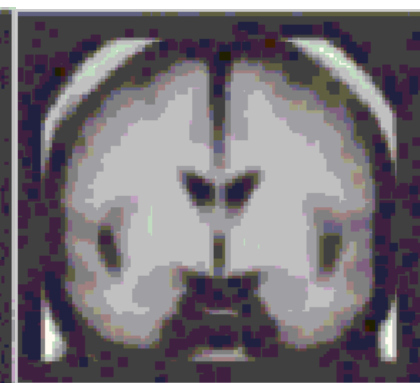

Thresholding

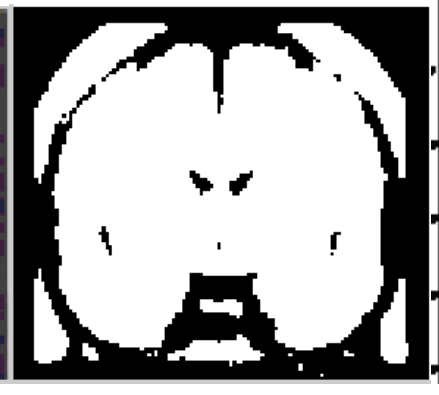

Segmentation \&Morphological operation

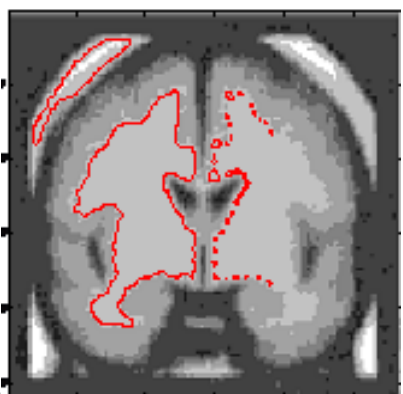

Output image

Figure 11. Input image and processed output images for control people.

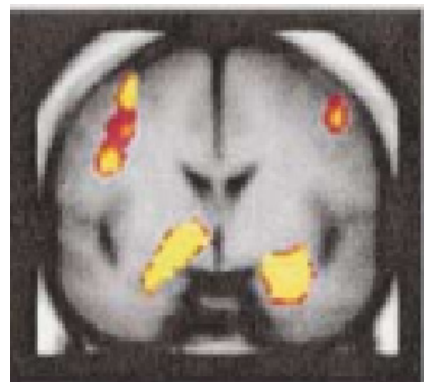

Input image

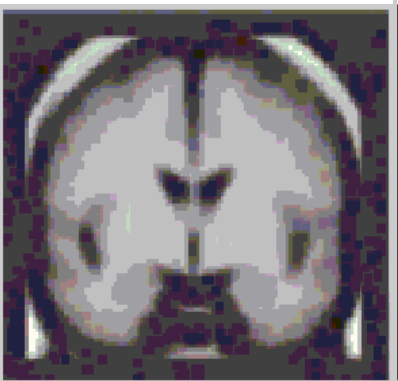

Thresholding

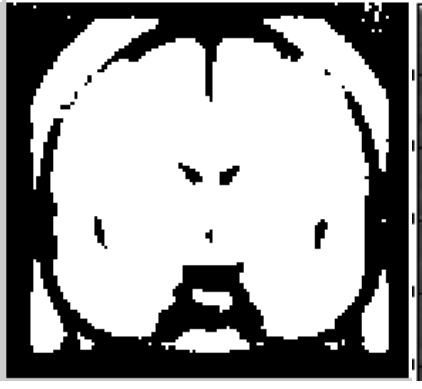

Segmentation \&Morphological operation

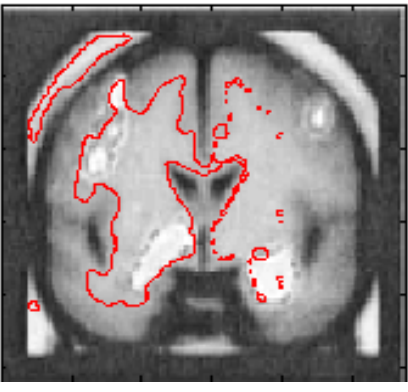

Output image

Figure 12. Input image and processed output images for Autistic people.
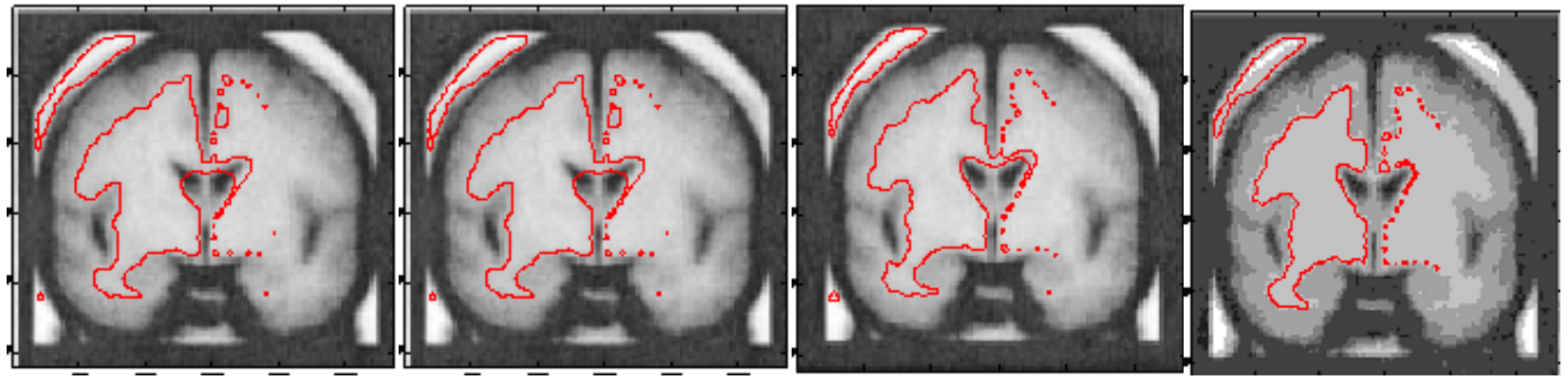

Figure 13. All Output images for control people. 

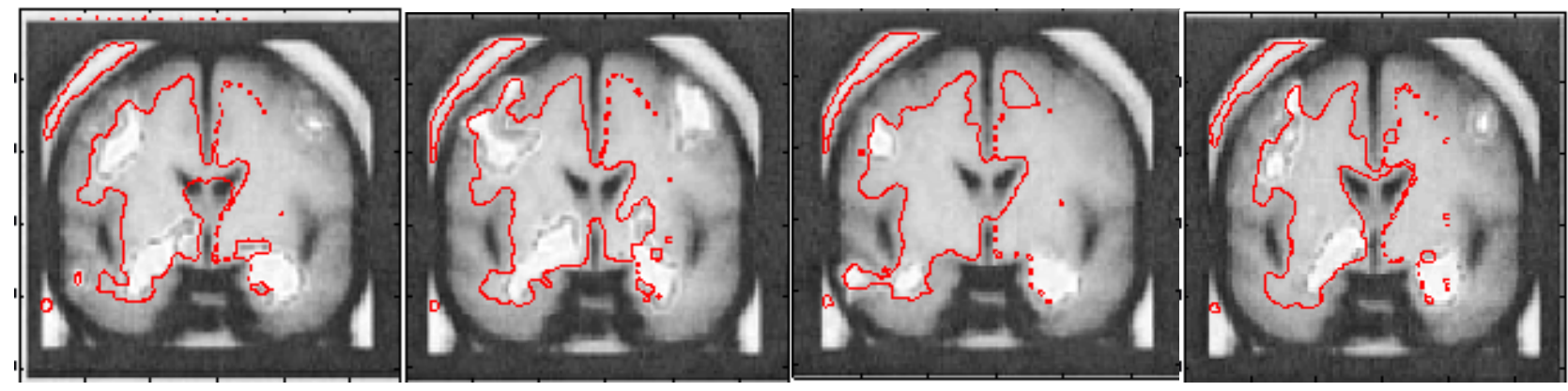

Figure 14. All output images for Autistic people.

Output images shows that the amygdala activation levels for neutral, happy, fear and sad facial expressions of autistic group are greater than normal people.

The amygdala is one of the most studied brain regions in behavioral neurobiology and is thought to be a critical element in the systems that generate fear/anxiety and the systems that modulate vigilance. The finding is that left amygdala reactivity is abnormal in autistic patients compared with control group as compared by other researcher [26], is consistent with findings that the amygdala is also hyper reactive in mood and anxiety disorders.

The following figure indicates black bar is for autistic people and white bar is for normal people.

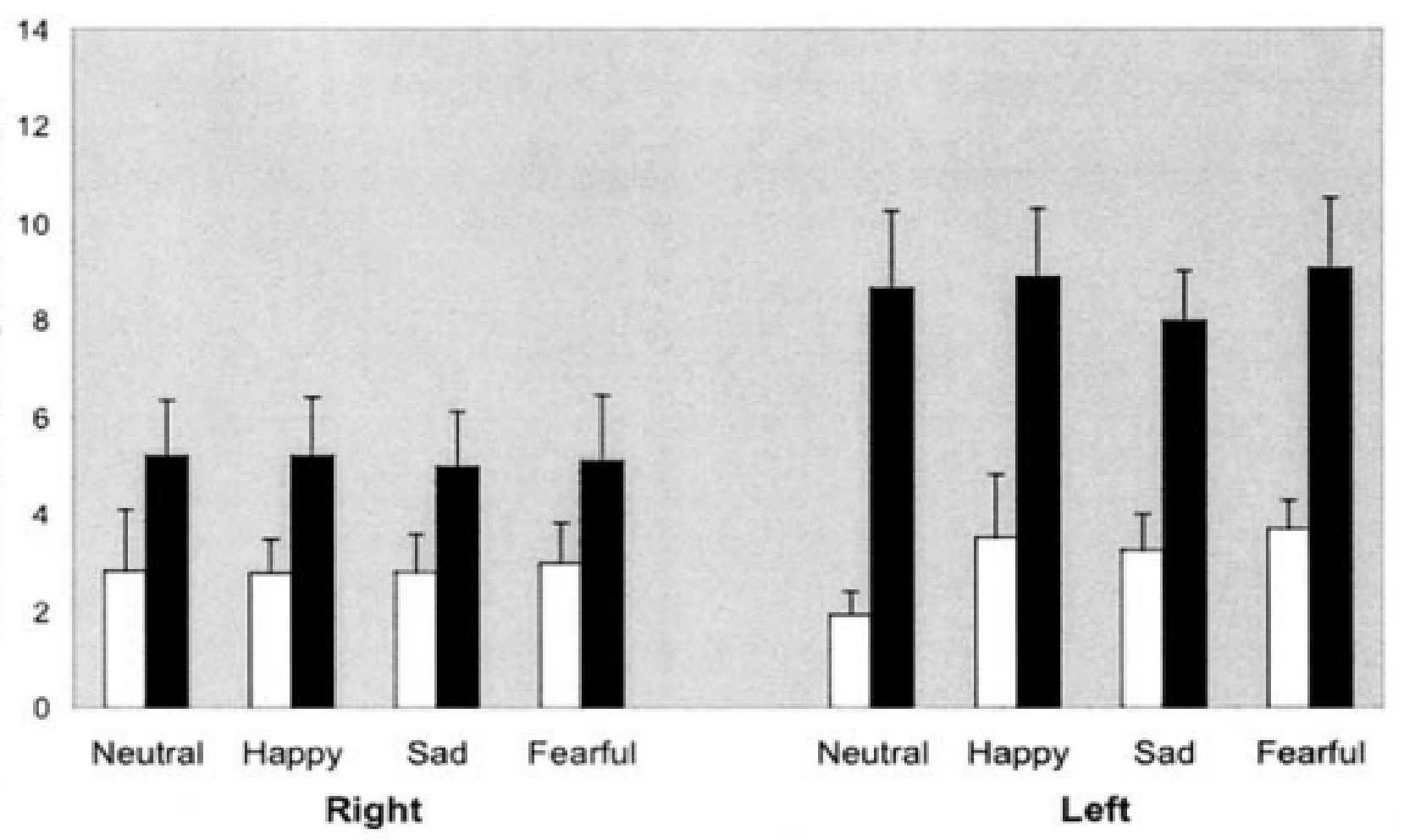

Figure 15. Mean levels of right and left amygdala activation in the autistic group and normal group to the four facial expressions.

\section{Conclusions}

By applying the level set method on fMRI images of control and autistic individuals, it is clearly visualized that there are differences in amygdala activation for four fixation such as Neutral , Happy, Sad and Fearful . From the fMRI images, it is clearly visualized that AMG of control people is significantly active than autistic. To make it more understandable, molecular investigations are of prime interest in future.

\section{REFERENCES}

[1] American Psychiatric Association, 1994. Diagnostic and statistical manual of mental disorders, fourth ed. (DSM-IV). American Psychiatric Association, Washington, DC.

[2] Volkmar, F., Lord, C., Bailey, A., Schultz, R.T., Klin, A., "Autism and pervasive developmental disorders" J. Child Psychol, Psychiatry 2004, 45 (1), 135-170.

[3] Baron-Cohen S, Ring H, Moriarty J, Schmitz B, Costa D, Ell P.Recognition of mental state terms. Clinical findings in children with autism and a functional neuroimaging study of normal adults. Br J Psychiatry 1994; 165: 640-9. 
[4] Kanwisher N, Stanley D, Harris A. The fusiform face area is selective for faces not animals. NeuroReport 1999; 10: 1837.

[5] Schultz RT. Developmental defecits in social perception in autism: the role of the amygdala and the fusiform face area. Int J Dev Neurosci 2005; 23:125-41.

[6] Pierce K, Müller RA, Ambrose J, Allen G, Courchesne E. Face processing occurs outside the fusiform 'face area' in autism: evidence from functional MRI. Brain 2001; 124: 2059-73.

[7] Pierce K, Haist F, Sedagat F, Courchesne E. The brain response to personally familiar faces in autism: findings of fusiform activity and beyond. Brain 2004; 127: 2703-16.

[8] Bolte S, Hubl D, Feineis-Matthews S, Prvulovic D, Dierks T, Poustka F. Facial affect recognition training in autism: can we animate the fusiform gyrus? Behav Neurosci 2006; 120: 211 6.

[9] Dalton KM, Nacewics BM, Johnstone T, Scheafer HS, Gernsbacher MA, Goldsmith HH, et al. Gaze fixation and the neural circuitry of face processing in autism, Nat Neurosci 2005; 8: 519-26.

[10] David G. Amaral, Ph.D. and Blythe A. Corbett, Ph.D. The Amygdala, Autism and Anxiety, To be published as part of the Novartis Foundation Symposium 251, "Autism: Neural Basis and Treatment Possibilities", June 2002.

[11] Claire O'Loughlin and Paul Thagard. Autism and coherence: A computational model In Mind \& Language, Vol 15(4), Sep 2000, 375-392. Available: http://dx.doi.org/10.1111/1468-0017.00140

[12] Michael S. C. Thomas, Victoria C. P. Knowland \& Annette Karmiloff-Smith. Explaining the mechanism of developmental regression in autism and the broader phenotype: a neural network modeling approach in American physiological association. 2011, Vol. 118, No. 4, page 637654.

[13] Matthew J. Altiere, Family functioning and coping behaviors in parents of children with autism. Thesis (M. S.). Eastern Michigan University, 2006.

[14] Norbert Michael Mayer ${ }^{1}$ and Ian Fasel ${ }^{2}$ Autism as an impairment in detecting invariants, ${ }^{1}$ National Chung Cheng University, ${ }^{2}$ University of Arizona, Tucson, USA in IEEE $9^{\text {th }}$ international conference. 18-21 aug, 2010. Pages 269-273.

[15] Courchesne E, Pierce K (2005a), Brain overgrowth in autism during a critical time in development: implications for frontal pyramidal neuron and interneuron development and connectivity. Int J Dev Neurosci 23:153-170.

[16] Just MA, Cherkassky VL, Keller TA, Minshew NJ: Cortical activation and synchronization during sentence comprehension in high-functioning autism: evidence of underconnectivity. Brain 127, 1811-1821 (2004).

[17] Friedman SD, Shaw DW, Artru AA, Richards TL, Gardner J, Dawson G, Posse S, Dager SR (2003). Regional brain chemical alterations in young children with autism spectrum disorder. Neurology60:100-107.

[18] S. Baron-Cohena, H.A. Ringb , E.T. Bullmorea , S. Wheelwrighta, C. Ashwina, S.C.R. Williams, The Amygdala Theory of Autism, Neuroscience and Biobehavioral Reviews 24 (2000) 355-364.

[19] Simon Baron-Cohen, Howard A. Ring+, Sally Wheelwright, Edward T. Bullmore++, Mick J. Brammer++, Andrew Simmons, and Steve C.R. Williams, Social intelligence in the normal and autistic brain: an fMRI study, This paper appeared in the European J. of Neurosci., 1999, 11, 1891-1898.

[20] Yi-Shin Chang, Julia P. Owen ,Shivani S. Desai, Susanna S. Hill, Anne B. Arnett, Julia Harris, Elysa J. Marco , Pratik Mukherjee, Autism and Sensory Processing Disorders: Shared White Matter Disruption in Sensory Pathways but Divergent Connectivity inSocialEmotionalPathways,Published:July30,2014,DOI10.1 371/journal.pone. 0103038

[21] Cynthia M. Schumann, Melissa D. Bauman, and David G. Amaral, Abnormal structure or function of the amygdala is a common component of neurodevelopmental disorders, Neuropsychologia. 2011 Mar; 49(4): 745-759. Published online 2010 Oct13. doi:

10.1016/j.neuropsychologia.2010.09.028

[22] M Davis1 and PJ Whalen2, The amygdala: vigilance and emotion, Molecular Psychiatry (2001) 6, 13-34.

[23] Osher, S.; Sethian, J. A. (1988), Fronts propagating with curvature-dependent speed: Algorithms based on HamiltonJacobi formulations, J. Comput. Phys. 79: 12-49, doi:10.1016/0021-9991(88)90002-2.

[24] Stanley Osher, Ronald P. Fedkiw, Level Set Methods: An Overview and Some Recent

Results,September5,2000,Available:http://physbam.stanford. edu/ fedkiw/papers/cam2000-08.pdf, Accessed [22August.2015]

[25] Erosion,

[Online],Available:http://homepages.inf.ed.ac.uk/rbf/HIPR2/ erode.htm, Accessed: [22 December, 2012]

[26] Cynthia M. Schumann, Melissa D. Bauman, and David G. Amaral, Abnormal structure or function of the amygdala is a common component of neurodevelopmental disorders, Neuropsychologia. 2011 Mar; 49(4): 745-759. 